Original Research Paper

\title{
The Human Resource Approach to Innovation in the Recent Growth of Floriculture Sector in Rural Areas of Sicily
}

\author{
Allegra Valeria, Pecorino Biagio and Zarbà Alfonso Silvio \\ Department Agriculture, Food and Environment, University of Catania, Catania, Italy
}

Article history

Received: 9-11-2017

Revised: 21-11-2017

Accepted: 24-2-2018

Corresponding Author:

Zarbà Alfonso Silvio

Department Agriculture, Food

and Environment, University of

Catania, Catania, Italy

Email: zaba@unict.it

\begin{abstract}
The variety and variability of the most commonly recognized innovation categories (product, process and management) have been the structural basis of the recent growth of floriculture sector in Sicily. However it is due to the virtuous character of farmer (vision, knowledge, skills and abilities) the ability to integrate the specific functions involved of the farm with innovation. As well as that, fundamental the relational behaviors within external environments characterized by non-deterministic stimulationresponse mechanisms. This paper presents the main results of a motivational investigation of the figure of the farmer of the floriculture sector in Sicily.
\end{abstract}

Keywords: Human Capital, Social Capital, Innovations, Floriculture

\section{Introduction}

Floriculture is one of the most dynamic agricultural compartments in the world, so that on the international markets the current trend of the relative products appears to be growing steadily as well as constantly changing both in terms of investments, in terms of number of companies and gross saleable production values. This is one of the most important sector not only internationally, but also in Europe, regarding both the turnover and the employment; Italy plays an indispensable role and Sicily contributes more than other regions in terms of areas invested. According to the official statistics sources, floriculture sector (i.e. the cultivation of flower and ornamental plants into vases) covers a total area of around 546,000 hectares (AIPH, 2011), equivalent to the $40 \%$ of the "floriculture and plant nursery" industry in complex (which also includes investments for nurseries and bulb-tubers). The world's monetary value of the latter industry has recently been estimated at 77 billion of euros, while Europe contributes with 18.3 billion of euros (EUROSTAT, 2012). Italy reach the $18 \%$ of the European cultivated areas and the $14 \%$ of its monetary value. After this brief necessary illustration about the production system in the world, we will now focus on the aim of this paper. The floriculture industry in Sicily has recently been affected by a profound and incisive development in terms of production, due to the remarkable technological changes for the ever-expanding use of innovations and business creativity. The floriculture farms have different structural and managerial features (Di Vita et al., 2015), which rely on two production models. One of the models consists of small firms (Allegra et al., 2015) with predominantly labour-intensive organization and management features, commonly found in specific rural areas of Sicily, which are territorially well-defined and where people and systems interact in different forms (Allegra et al., $2014 \mathrm{~b}$ ). The localization factor is given to the widespread presence of floriculture farmers and in the wider circulation of useful information for farms. Another model is ruled by medium/large enterprises, which is both purely agricultural and most likely industrial (capital intensive) in terms of structural characteristics and management. This combination of organizing and managing businesses gives rise to productive systems that have material and technological resources value generating. (Di Vita et al., 2015). Units of production not related to a well-defined rural geographic area are part of this model. The localization factor for these floriculture farms depends on the living conditions of the local system or it derives from productive diversification strategies (Allegra et al., 2014a), even with initial business skills and knowledge not related with floriculture (Zarbà et al., 2015). Hence, a multiplicity of competitive options distinguishes the many-sided floriculture industry as a result of both the high technological level within the enterprise, suitable for different articulations and organizational modalities and the wide variety of products made by species and typology; the combination of the two comply with a competitive market scenario (Park et al., 2017) characterized by deep and unpredictable discontinuities. Farms of the floriculture industry are, in fact, a very 
differentiated aggregate; they produce cut flowers, flowering plants, green plants that in turn differentiate themselves in numerous merchant addresses (leafy and cut foliage plants, potted plants, etc.), as well as being extremely dynamic. It is recalled that such agricultural products are not essential (unnecessary goods) and so trends exert strong influence on them, which is why the future is constantly changing. The competitive advantage requires the necessary support (Casanova and De Vita, 2007) of both company's tacit and explicit knowledge (Sassu and Lodde, 2003) when its competition shows its action (Lanfranchi and Giannetto, 2015). Therefore, contextual conditions conducive to innovation in products and processes (both open innovation and closed innovation) that enable companies to be more competitive, even hipercompetitive (Allegra et al., 2014c) whose competitive advantage (originality and timeliness) could still be a limited milestone, to the point where further new initiatives are needed (Baccarini et al., 2012). For all these reasons, the grower versatility is fundamental. Specifically, we refer to a core competence that in a horizontal way, between models, techniques and practices, crosses the market and production functions (mainly agricultural) of unnecessary goods (especially non-agricultural relationships) with which the enterprise communicates and reaches (Pappalardo et al., 2014). That briefly described above has given importance to the scientific research fulcrum of this work, since the main topic man-innovation relationship in the floriculture industry, as far as we are aware, it has not yet been extensively studied. However, it is not to think that the results of this survey can exhaustively take on the relational issues of an industry with multiple and dynamic product combination and governance over time and space (Vastola et al., 2017). Down below, we try to propose some of the possible ways in which the human capital of Sicilian "flower and ornamental plant" farms is facing innovations; with the aim of differentiating the different approaches to innovation and not developing the arguments between innovative firms and noninnovation firms. The text provides a necessary first synthetic part about the main structural features of the farms and the farmer's demographic characteristics; the second and central section focuses on the prevailing business paths that guide innovation.

\section{Materials and Methods}

The remarkable heterogeneity existing in the territorial and business features floriculture farms in Sicily has suggested the possibility of conducting preliminary territorial reconnaissances on production sites to acquire knowledge of the cognitive and interpretative nature of the production units. Among them, the size of the productive surfaces in the complex and the main structural characteristics of the farms that are the constituents of the industry examined. Business surveys, which have been launched since 2015, have been concentrated on the main rural areas of production (preliminarily identified by various public bodies in the agricultural sector) (Allegra et al., 2014a; Selvaggi et al., 2017), which signify a considerable thickening of the flower and ornamental plants surfaces. The most appropriate way of conducing this survey appears to be the linguistic one, since this is a production context where the guidelines are often the result of different business philosophies, the mercantile combinations are innumerable and the structural business features are heterogeneous with many variables. Indeed, before resorting to this method, among the various possibilities offered by the methodology of statistical analysis, the traditional investigation was tested on a first functional sample of farms, but when conducting some difficulties emerged, sometimes insurmountable. The reasons why this happened is, above all, the attitudes of the growers invited to the standardized interview, to express strong resistance to collaboration, for the concern to expeditiously address the questions asked, preferring an extemporaneous conversation of what concerns the strategic orientation about the sources of competitive advantage (know how) and business. This is the main motivation that has set the conditions for a textual analysis, whose conclusions are more subjective and use a lot of tacit knowledge (Cipriani, 2016). Then, the individual direct inquiry was turned into a discoursebased research, based on spontaneous informal logical reasoning (logical-argument method). The surveys were carried out in a three-year period, 2015/2017, with the help of a specific questionnaire closed in the sociodemographic part (for the distinguishing features of the entrepreneur and the structural characteristics of the companies). It was also open-unstructured regarding topics about the information of the factors that determine the decisions of the firms for innovation (which has the advantage of obtaining great concreteness in the aspects considered). However, it was a detection tool designed to optimize the reasoning of possible innovations in the enterprise, for the purpose of sustainability of the competitive edge (Zecca and Rastorgueva, 2017). Indeed, with the dialectical investigation, in dealing with the key phenomena for competitiveness, we have been able to note the changes ranging from production, quality, flexibility and relationships. Changes that involve a variety of business decisions regarding the cultivation and/or the design of floriculture products (soil, pots, pans), materials management, human resource management, management of information, transportation management, marketing strategy management and in particular relationship management between suppliers and customers. A journey into the activities of the floriculture farmers where personal skills, genius, inventive spirit, creative audacity (human capital), personal information and contacts (social capital) of the entrepreneur rule the business strategy 
(Zarbà et al., 2013). In this way, the quality of the research is largely due to the professionalism and the communicative ability with which the detector performs his task. About the disadvantages of this particular kind of survey, based on open questions, though it is richer in information, it can lead to problems regarding both the recording and the interpretative part. Therefore, in order to ensure the authenticity of the information collected, it was appropriate to refer to two personal conditions of detection; the first, subjective, recalls the value-driven and cultural elements matured by theoretical concepts of school education and learning outcomes; the second, objective, recalls modalities, methods and techniques or experiences from professional and/or operative activities. Negative feature of the detection method adopted is the influence of the detector's personality and, above all, of the interviewee. The administration and distribution of the questionnaire for interviews was favoured by the circumstance of territorial reconnaissance, because during the meetings with growers, some of them made themselves available at the same time for a narrative conversation on the proposed topics. As regards the description of the results collected, it was necessary to circumscribe the aim of the topics discussed, namely to contextualize the information to make objective the argumentative essay. In other words, it was necessary to cumulate and articulate arguments to avoid the risk of identifying different information with the same function instead of different types of information. In essence, this is a procedure to provide a more synthetic and organized information to identify human resource trails between constraints and opportunities for enterprise innovation, in order not only to get close to the knowledge of reality, but also to get away from mistakes. Finally yet importantly, it is good to know that the survey did not concern the farmers for the supply of seedlings at the early stages of production (core product) i.e. semi-finished; as these which farms in general links the activity to a specific intermediate market. The these farmers use of all the opportunities originating from new products and new technologies transmitted by other companies with production cycles restricted to the final phase of lcoltivation of floriculture products. Infact, the farmers of "semi-finished" business contributes significantly to the successful competitive advantage of part of the Sicilian floriculture farmers that they operate almost exclusively on the final market (Lanfranchi et al., 2015).

\section{Results}

The preliminary territorial inquiry conducted in the three-year period 2015/2017 in Sicily revealed a great variety of the companies' arrangement. In fact, it is difficult to find production standards that respond to structural, organizational and managerial characteristics and that conform to certain types that can be categorized by nature and destination into ordered groups of flora and fauna production units. This is also the case where companies are organized between floricultural productions and ornamental productions; in particular, the main production sectors are represented by the "flowers and cut foliage plants production chain" and "indoor ornamental green and flowering plants supply chain" as well as "outdoor ornamental plants supply chains". The main rural areas where floriculture firms are located are geographically distributed along the perimeter coast of Sicily, which according to our estimates would extend to a total of about 2,500 hectares. These are rural areas selected for favourable environmental conditions characterized by a mild climate and high availability of good quality irrigation. Each territory is also characterised by the high level of production specialization of the companies that are located there. In particular, rural areas are located: along the coast of the province of Messina (with 630 hectares of cultivated and ornamental surfaces, which are characterised by citrus production and ornamental olive trees); along the eastern coast of the province of Catania until the border with the province of Syracuse (with 1370 hectares predominantly with the production of palms, bougainvillea, as well as for a wide assortment of Mediterranean plants); on the western coast of the province of Trapani (with about 260 hectares mainly characterised by potted green foliage plants); and along the south coast of the province of Ragusa (with 130 hectares of cut flowers and annual flowering plants). In addition, it is also important to mention that there are other horticultural oasis located here and there in Sicily. The farmers of the floriculture sector, as noted in the surveys, have a wide diversification of products with strong specialization of the types of flowers and/or ornamental plants (the latter mostly in containers, i.e. in pots or pellets) to the point that they are identified as a proper production chain. Additionally, although the production chains are generalized for product types, each one can also be distinguished in ranges because of innovative product and process engineering. These are strategies or tactics applied to avoid excessive competition on the same type of product that in the short term could harm the companies concerned, while long lasting it could harm the structural company's arrangement. Organizational and management circumstances that, for the activities that have to be carried out, require the potential of quality of the single human resource subjects with the capacity to develop new abilities regarding innovative elements. Therefore, it is significant the awareness of being part of a gear of a complex production context that is in continuous development. This is why the decision-making autonomy is so important in performing a specific function assigned, as well as the intrinsic motivational potential of satisfaction and involvement to operate the performance. These are the personal responsibilities and the sense of belonging to a complex production reality that surveys have revealed among the surveyed growers of all ages. The average age of the entrepreneur is 53 
years old; the prevalent age range is between 50 and 60 years old (pioneers of the development of floriculture in Sicily). A small number is represented by young people, the youngest interviewed with a role in the corporate governance is 29 years old. The prevailing professional level is represented by practical knowledge provided by experience, while the most popular level of education is the professional diploma, not necessarily related with agriculture. The master's degree is mainly found among the thirties, few among the oldest. However, information is entrusted to industry magazines, modern media and/or suppliers, with which often there are strong and differentiated relationships of collaboration. Entrepreneurs need continual updating so that human resources can efficiently and effectively help to make the introduction and/or the application of innovations. The latter mainly concern interventions of differentiation or diversification of floriculture products; moreover, since the production cycles are in short time spans (up to 5-6 years for potted ornamental plants), farmers also resort to conglomerate diversification innovations. So, in order to achieve competitive advantages (differentiation and/or related diversification) or comparative advantages (conglomerate diversification), farmers, as is often the case, are in a constant state of alert with threats and opportunities from the environment. This starts a continuous and active research about business occasion and consequently a continuous gathering of evaluation information and ultimately decision-making (Baccarini et al., 2012). In particular, the use of innovations can relate to floriculture products already on the market where aesthetic adjustments and/or enhancements allow to strengthen the competitive position resulting in an increased demand (market penetration strategies), namely innovations that allow to entry into new markets from a geographical point of view or from different buyers (market development strategy). Otherwise, the farmer can be innovative by improving the production process in terms of effectiveness and efficiency and so in terms of costeffectiveness, or by improving the structures in view of new performances both on existing business products and on new products, for the market (process innovations complementary to product innovations). The interdependence among the innovative domains highlights the importance of human resources in relation to the new integration links of production functions involved in innovation. In essence, product innovations can affect all the production chains, as long as there is a logical relationship with human resources about the executive work and provided that they are agile and adaptable to change. Facing this scenario of dynamic productive activities, enhancing the internal skills of human capital is surely a particularly important condition for the floriculture farms about production functions, but this is not enough to achieve the goals of competitive advantage; in fact, the firm must make choices that are constrained by external constraints that mainly concern decisions. Relational relationships that come from both the market of factors (suppliers) and the final market (customers), elusive by establishing new relationships according to rules that facilitate collaboration (social capital of reciprocity). At this point, we have to underline that no matter which typology of innovation it is (if it allows the achievement or the expansion of preexisting market or if it allows the formation of prices that the market can accept - from product to process and vice versa from process to product) it always transforms the organization that had produced it.

\section{Conclusion}

From our results, is perhaps more clear the role of the human resource in managing the innovations useful both to support competitive confrontation (constraint) and to emerge and differentiate (opportunities) on the floriculture market. In other words, the floriculture sector in Sicily has skills, that is a system of skills, knowledge and experiences aimed at guiding change and managing the company in the complexity of the indoor and outdoor environment of the production unit itself. Concretely, it is possible to assure the formation of business skills combinations in order to gather the most quantity of innovative signals and tools from suppliers, customers, competitors, different economic operators in the relational environment and so on. All this is based on the assumption that in this kind of industry there are organizational skills able to create the conditions to involve all the human components of the internal structure of the enterprise considered. However, the corporate management system for skills is not found in the universe of floriculture farms in Sicily, either in relation to real references or to more personal reason, or complementary to the other. In particular, this is due to the great variety of existing structural settings and to some fundamental values, which in the floriculture sector cannot always be found. It should be emphasized, however, that the use of tout court innovations implies skills that relate to human abilities that are not part of the company context; it is not possible to know how to be in business without knowing how to be general (business skills must be the same of the interpersonal skills). In general, however, the study has shown and confirmed that floriculture farms in rural areas of Sicily are located among those farms that contribute more to local development, especially when the human resource - by eclectic professional levels - it is innovation itself.

\section{Acknowledgement}

Works have been supported by University of Catania, Italy. Department Agriculture, Food and Environment.

\section{Author's Contributions}

Zarbà A.S.: Introduction. 
Allegra V.: Materials and Methods, Results.

Pecorino B.: Conclusion.

\section{Ethics}

The corresponding author confirms that all of the other authors have read and approved the manuscript and there are no ethical issues involved. This article is original and contains unpublished material.

\section{References}

AIPH, 2011. International Organization of Horticultural Producers, Statistical Ye $\neg$ arbook.

Allegra, V., S. Bracco and A.S. Zarbà. 2015. Environmental sustainability of agri-food SMEs. The case of dairy enterprises. Quality Access Success, 16: 172-179.

Allegra, V., C. Bellia and A.S. Zarbà, 2014b. The logistics of direct sales: New approaches of the EU. Italian J. Food Sci., 26: 443-450.

Allegra, V., C. Bellia and A.S. Zarbà. 2014a. Direct sales as a tool for competitiveness for SMES in the EU. The case of farms "ornamental floriculture and nursery products. Quality Access Success, 15: 19-24.

Allegra, V., G. Pappalardo and A.S. Zarbà, 2014c. Hypercompetition for farms? The new use connect "to ornament and for edible" of plants Mediterranean potted. Proceedings of the International Multidisciplinary Scientific Conferences on Social Sciences and Arts, Sep. 1-9, Bulgaria, pp: 317-324. DOI: 10.5593/sgemsocial2014/B24/S7.041

Baccarini, C., E. Giaretta and F. Brunetti, 2012. Corporate governance between principles, models, techniques and practices. G. Giappichelli Editore, Torino. ISBN/EAN: 978-88-348-2822-9, pp: 448.

Casanova, T. and A. De Vita, 2007. Knowledge management of SMEs: hidden treasure. FrancoAngeli. ISBN: 9788846485991, pp: 144.

Cipriani, R., 2016. New sociology manual Maggioli Editore. ISBN/EAN: 8891616401/9788891616401, pp: 260.

Di Vita, G., V. Allegra and A.S. Zarbà. 2015. Building scenarios: A qualitative approach to forecasting market developments for ornamental plants. Int. J. Bus. Globalisation, 15: 130-151.

DOI: 10.1504/IJBG.2015.071152
EUROSTAT, 2012. Working document advisory group, Flowers and ornamental plants.

Lanfranchi, M. and C. Giannetto, 2015. A case study on the role of farmers' markets in the process of shortening the food chain and the possible economic benefits for consumers. Quality Access Success, 16: 94-98.

Lanfranchi, M., C. Giannetto and A. De Pascale, 2015. Information asymmetry on rfid system in the Agrifood Sector: A study of consumer behavior. Quality Access Success, 17: 73-77.

Pappalardo, G., V. Allegra and B. Pecorino, 2014. A longitudinal analysis of globalization and regionalization in international trade of nursery gardening products: A social network approach. Quality Access Success, 15: 83-89.

Park, H..S., B. Min and S.H. Oh, 2017. Research trends in outdoor pig production. Asian Australasian J. Animal Sci., 30: 1207-1214. DOI: 10.5713 /ajas. 17.0330

Sassu, A. and S. Lodde, 2003. Local knowledge, innovation and economic development: the experience of Southern Italy. FrancoAngeli. ISBN: 9788846444356, pp: 432.

Selvaggi, R., M. Parisi and B. Pecorino, 2017. Economic assessment of cereal straw management in Sicily. Quality Access Success, 18: 409-415.

Vastola, A., P. Zdruli, M. D'Amico, G. Pappalardo and M. Viccaro et al., 2017. A comparative multidimensional evaluation of conservation agriculture systems: A case study from a Mediterranean area of Southern Italy. Land Use Policy, 68: 326-333.

DOI: 10.1016/j.landusepol.2017.07.03

Zarbà, A.S., G. Di Vita and B. Pecorino, 2015. Business performance in the ornamental plants industry: A supply chain approach. Quality Assess Success, 16: 9-16.

Zarbà, A.S., G. Di Vita and V. Allegra, 2013. Strategy development for Mediterranean pot plants: A stakeholder analysis. Quality Access Success, 14: 52-58.

Zecca, F. and N. Rastorgueva, 2017. Knowledge management and sustainable agriculture: The Italian case. Quality Access Success, 18: 97-104. 